Received: Apr 06, 2019; Accepted: Apr 26, 2019; Published: May 30, 2019; Paper Id.: IJMPERDJUN2019131

\title{
INTRODUCTION
}

Thermoelectric is defined as the generation of electricity from a given temperature difference or vice versa. Solid state devices capable of producing power, these devices are environment friendly that come with low maintenance and reliability. The concept of thermoelectricity can be classified into two parts. i.e. Thermoelectric Coolers (TEC) module and Thermoelectric Generators (TEG) module. When an electrical current passes through the unit module, a finite temperature difference is observed between two junctions. Temperature at one junction becomes higher than the ambient and at other junction lower than the ambient. This "power input to temperature difference" is known as the Peltier effect. Therefore, the cold junction can absorb thermal energy from reservoir and the hot junction can reject heat to surrounding environment. Thermoelectric cooling, also called "Peltier cooling" is a solid-state method of heat transfer through dissimilar semiconductor materials. Coefficient of performance for thermoelectric cooling system is discussed here with single stage thermoelectric module. TECs inherently have many advantages over the alternate types of refrigeration. Figure 1 shows the entire fabrication of thermoelectric cooling system. The general measure of efficiency of a TEC is based on the amount of heat that it removes compared to the amount of work that it requires. Matthieu Cosnier et al., [1] presented an experimental and numerical study of a thermoelectric air-cooling and air-heating system and were reported a cooling power of $50 \mathrm{~W}$ per module with a coefficient of performance (COP) in between 1.5 and 2 . The electrical 
intensity of 4 amps power input is supplied and maintained the $5^{\circ} \mathrm{C}$ temperature difference between the hot and cold sides. Suwit Jugsujinda et al.,[2] conducted an experiment to analyse COP of thermoelectric refrigerator performance. The refrigeration system of thermoelectric refrigerator(TER) with a size of $25 \times 25 \times 35 \mathrm{~cm}^{3}$ was fabricated by using a thermoelectric cooler (TEC) with a size of $4 \times 4 \mathrm{~cm}^{2}$ ) and applied electrical input power of $40 \mathrm{~W}$. The temperature of TER has decreased from $30{ }^{\circ} \mathrm{C}$ to $20{ }^{\circ} \mathrm{C}$ in one hour time period and slowly the cooling temperature dropped gradually. The maximum COP of TEC and TER were 3.0 and 0.65. Wei He et al., [3] done work on numerical study of Theoretical and experimental investigation of a thermoelectric cooling and heating system driven by solar. In summer, the thermoelectric device works as a Peltier cooler when electrical power input supplied by thermal photovoltaic modules. The air cooling temperature of $17{ }^{\circ} \mathrm{C}$ was achieved with $\mathrm{COP}$ of 0.45 with the thermoelectric device. Riff and Guoquan et al., [4] showed an experimental study of comparative investigation of thermoelectric air conditioners versus vapour compression and absorption air conditioners. Three types of domestic air conditioners were compared and fabricated a compact air conditioner. Nagyet et al., [6] focused on modelling and optimization of the thermoelectric heat sink with proper design of the thermoelectric cooling systems. Collectively, TE material researchers have spent tens of millions of dollars to advance the performance level of TE materials with some effective heat sink designs. The combination of detailed thermal modelling and high-speed personal computers makes it no less effort to fully optimize a heat sink design. Riffat and Qiu et al., [7] compared the performances of thermoelectric and conventional vapour compression air-conditioners. Results showed that the actual COPs of vapour compression and thermoelectric air-conditioners are in the range of 2.6-3.0 and 0.38-0.45, respectively. However, thermoelectric air conditioners have several advantageous features compared to their vapour-compression counterparts. Astrain, et. al., [8] steered the COP in the thermoelectric refrigeration by optimizing heat dissipation. Thermoelectric refrigeration based on the principle of a thermos syphon with phase change is also presented. In the experimental optimization phase, a prototype of thermo syphon with a thermal resistance of 0.110 $\mathrm{K} / \mathrm{W}$ has been developed, dissipating the heat of a Peltier pellet with the size of $40 * 40 * 3.9 \mathrm{~cm}^{3}$, experimentally proved that the use of thermos syphon with phase change increases the coefficient of performance up to 32\%. Shen, Xiao et al., [9] investigated a novel thermoelectric radiant air-conditioning system (TE-RAC). The system on thermoelectric airconditioner using Peltier Module employs thermoelectric modules as radiant panels for indoor cooling, as well as for space heating by easily reversing the input current. The commercial thermoelectric module they have obtained a maximum cooling COP of 1.77 with an electric input current of $1.2 \mathrm{amp}$. and obtained the recorded cold side temperature $20^{\circ} \mathrm{C}$. Virjoghe, Diana et al., [10] conducted a numerical investigation of thermoelectric System. The thermoelectric systems have attracted renewed interest as concerns with the efficient use of energy resources, and the minimization of environmental damage, have become important current issues. This paper presents of numerical simulation for several the thermoelectric materials. Numerical simulation is carried out by using a finite element package ANSYS. Maneewan et al., [11] conducted an experimental investigation on TEC1-12708 type of thermal comfort study of compact thermoelectric air conditioner. In this paper the cooling performance of compact thermoelectric air-conditioner was analysed. The compact TE air conditioners COP was calculated to its optimum parameters. Then analyse the COP with respect to time at various considerations. Manoj and Walke [12] conducted an experimental study of thermoelectric air cooling on cars by replacing the existing HVAC system with newly emerging thermoelectric couple or cooler which works on Peltier and Seebeck effect. Yadav and Mehta et al., [13] presented combined experimental and theoretical study of thermoelectric materials and its applications. The present study develops an optimization design method for thermoelectric refrigerator. This device is fabricated by combining the standard n- and p-channel solid-state thermoelectric cooler with a two-element device inserted into each of the two channels to eliminate the solid-state thermal conductivity. Manoj Kumar et al., [14] presented an 
experimental study of novel potential green refrigeration and air-conditioning technology to analyse the cause and effect of an existing air-condition system. Thermoelectric cooling provides a promising alternative R\&AC technology due to their distinct advantages. The available literature shows that thermoelectric cooling systems are generally only around 5-15\% as efficient compared to 40-60\% achieved by the conventional compression cooling system. Huang. B et al., [15] fabricated an experimental set up of thermoelectric cooler to analyse it at various operating considerations. The system simulation shows that there exists a cheapest heat sink for the design of a thermoelectric cooler. It is also shown that the system simulation coincides with experimental data of a thermoelectric cooler.

After studying the literatures on thermoelectric cooler modules from various publications, it was concluded that most of the researchers have focused directly on numerical studies, fabrication, experimentation and improvement of TEC module details to find out the COP of the Thermoelectric Cooler Module under varied operating conditions. Hence authors found a little bit gaps on modeling and analysis of thermoelectric cooler modules of various materials like Copper and Aluminium fins. It was tested with temperature and heat flux distributions under varied operating conditions.

\section{MODELING ANALYSIS}

The thermoelectric cooler (TEC) modules are modeled in CATIA and analyzed in ANSYS. The pictorial representations of TECs are shown in figures 1,2 and 3 with the selection of Aluminium and Copper fin type materials.
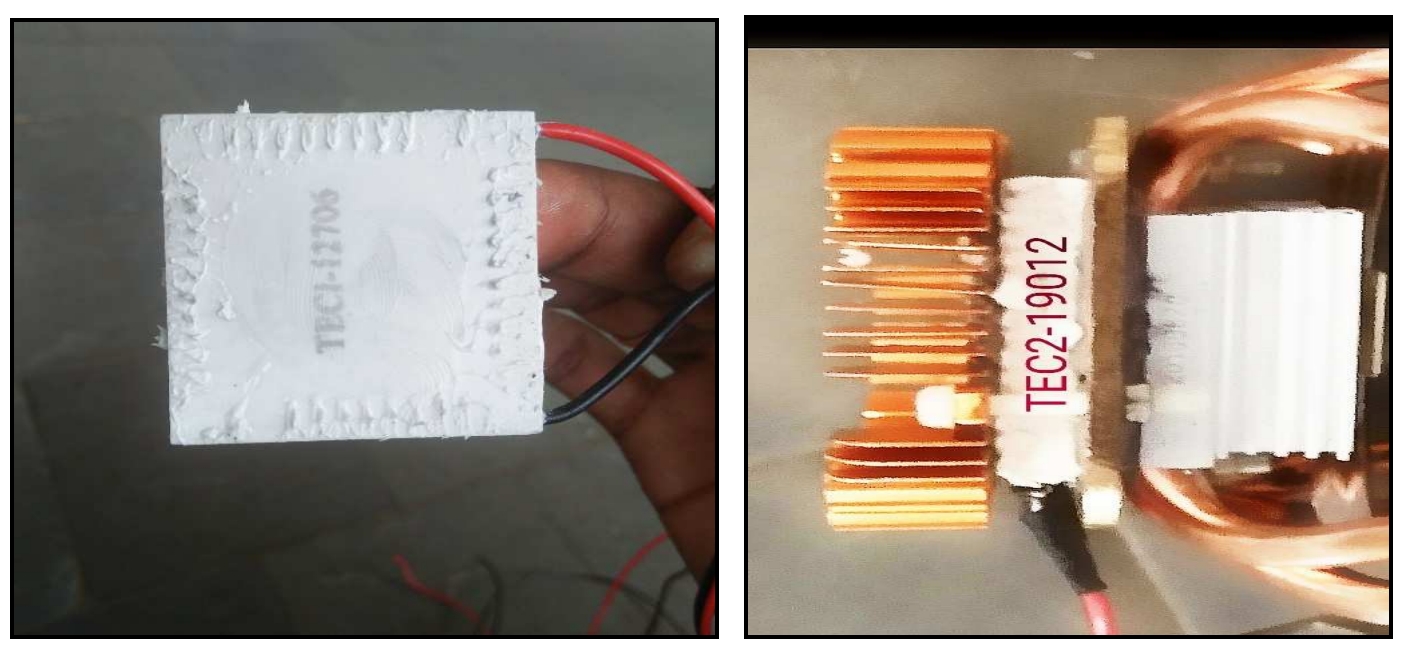

Figure 1: Pictorial Representations of Thermoelectric Cooler Modules
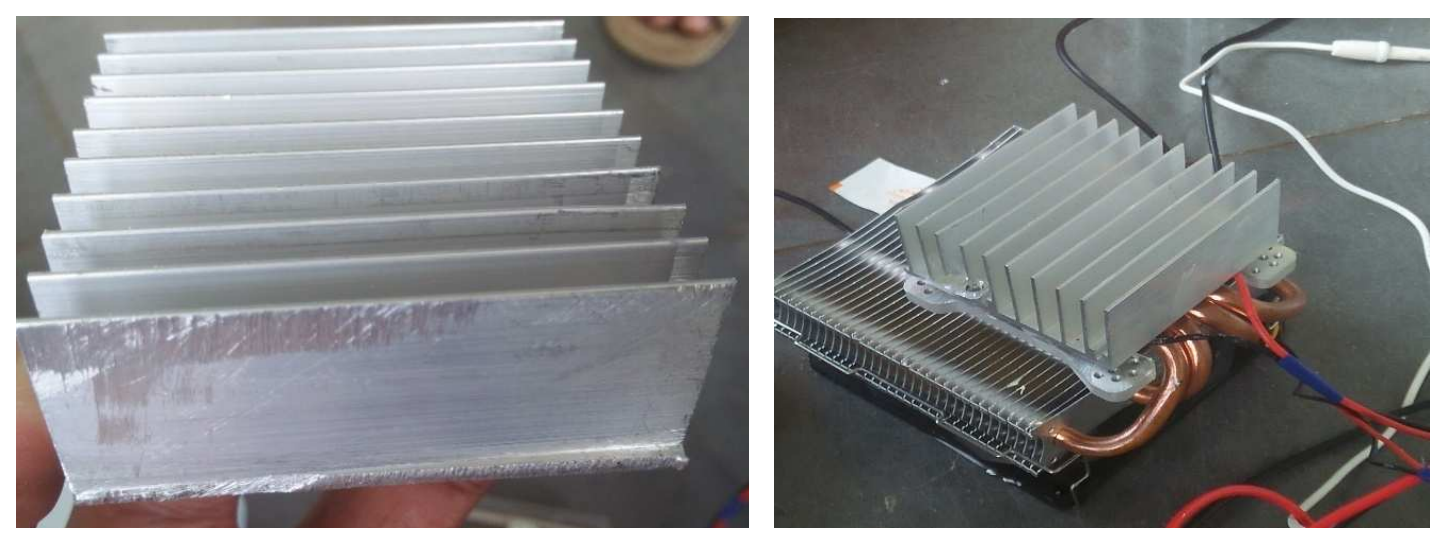

Figure 2: Pictorial Representations of Aluminium Fins on Thermoelectric Cooler Modules 

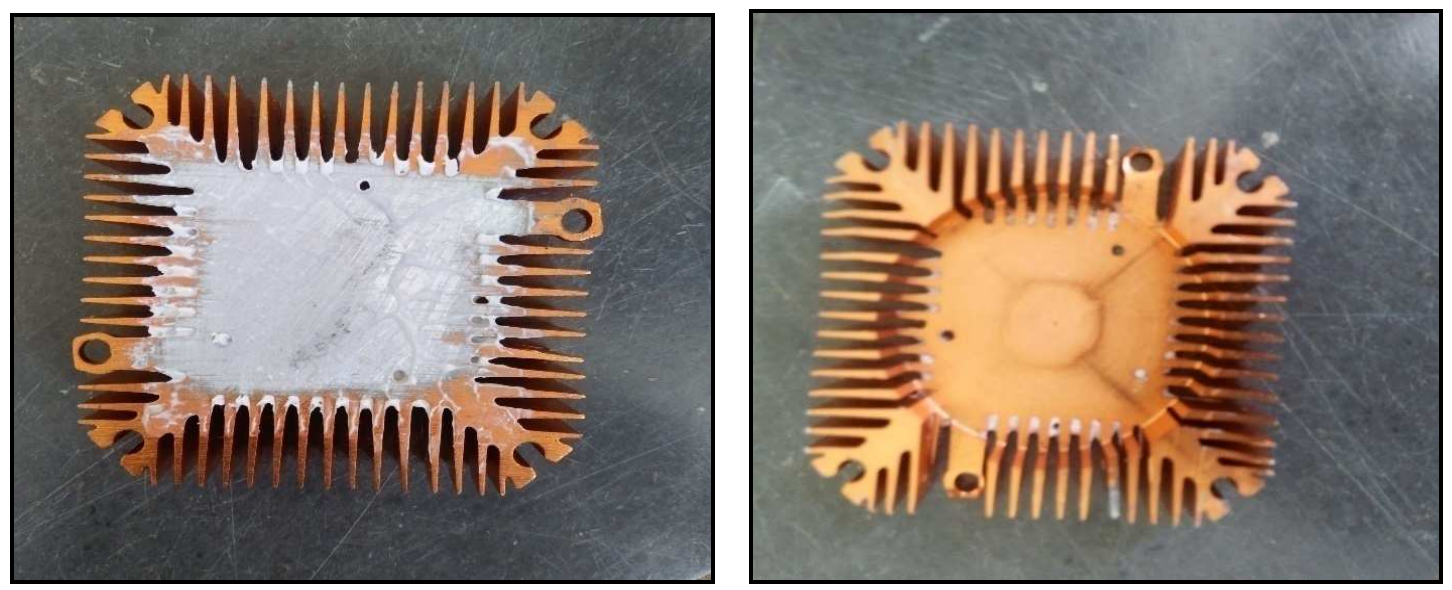

Figure 3: Pictorial Representations of Copper Fins on Thermoelectric Cooler Modules

Table 1: Model Specification and Parameter Estimation in Fixed Effect Model

\begin{tabular}{|c|l|l|}
\hline S. No & \multicolumn{1}{|c|}{ Name } & \multicolumn{1}{c|}{ Specifications } \\
\hline 1 & Material & $40 * 40 * 7.3$ \\
\hline 2 & Area dimensions $(\mathrm{mm})$ & 80 \\
\hline 3 & Maximum operating température $\left({ }^{\circ} \mathrm{C}\right)$ & $33.3 \mathrm{~W}$ \\
\hline 4 & Q $\max (\mathrm{W})$ & $12 \mathrm{~V}$ \\
\hline 5 & Vmax (DC) & 12 \\
\hline 6 & Imax (A) & $-55^{\circ} \mathrm{C}$ to $83^{\circ} \mathrm{C}$ \\
\hline 7 & Work environment temperature $\left({ }^{\circ} \mathrm{C}\right)$ & $-40^{\circ} \mathrm{C}$ to $60^{\circ} \mathrm{C}$ \\
\hline 8 & Storage condition & \\
\hline
\end{tabular}

Table 2: Specifications of Copper and Aluminium Fins on Thermoelectric Cooler Module

\begin{tabular}{|l|l|c|c|c|}
\hline S.No & \multicolumn{1}{|c|}{ Name } & $\begin{array}{c}\text { Copper Fin } \\
\text { Specifications }\end{array}$ & $\begin{array}{c}\text { Aluminium Fin } \\
\text { Specifications }\end{array}$ & Units \\
\hline 1 & Isotropic Thermal Conductivity & 386.7 & 237.5 & $\frac{\mathrm{W}}{\mathrm{m}-{ }^{o} \mathrm{C}}$ \\
\hline 2 & Density & 8940 & 2689 & $\frac{\mathrm{K}}{\mathrm{m}^{3}}$ \\
\hline 3 & Specific Heat Constant Pressure & 385 & 951 & $\frac{\mathrm{J}}{\mathrm{Kg}-{ }^{o} \mathrm{C}}$ \\
\hline
\end{tabular}

\section{STEADY STATE THERMAL ANALYSIS OF COPPER AND ALUMINIUM FINS ON THERMOELECTRIC COOLER (TEC) MODULE}

Fins are used to enhance the convective heat transfer in a wide range of engineering applications, and offer a practical means for achieving a large total heat transfer surface area. Fins are commonly applied for heat management in electrical appliances such as computer power supplies or substation transformers. Other applications include IC engine cooling; such as fins in a car radiator. It is important to predict the temperature and heat flux distribution within the fin in order to choose the best configuration that offers maximum effectiveness. This exercise serves as a visualization tool for evaluating the effect of shape on fin effectiveness, efficiency and temperature and heat flux distribution. Hence the ANSYS/Thermal products support steady-state thermal analysis. A steady-state thermal analysis calculates the effects of steady state thermal loads on a system or component. Engineer/analysts often perform a steady-state analysis before doing a transient thermal analysis, to help to establish initial conditions. A steady-state analysis can also be the last step of a 
transient thermal analysis. Steady-state thermal analysis can be performed to determine temperatures, thermal gradients, heat flow rates and heat fluxes in an object are caused by thermal loads. A steady-state thermal analysis may be either linear with constant material properties; or nonlinear with material properties that depend on temperature. The thermal properties of most material do vary with temperature. So the analysis usually is nonlinear. Steady state analysis of the copper and aluminium fins on Thermoelectric Cooler (TEC) Module performance were carried and compared under the electric input current supply of 6 and 3 amperes.
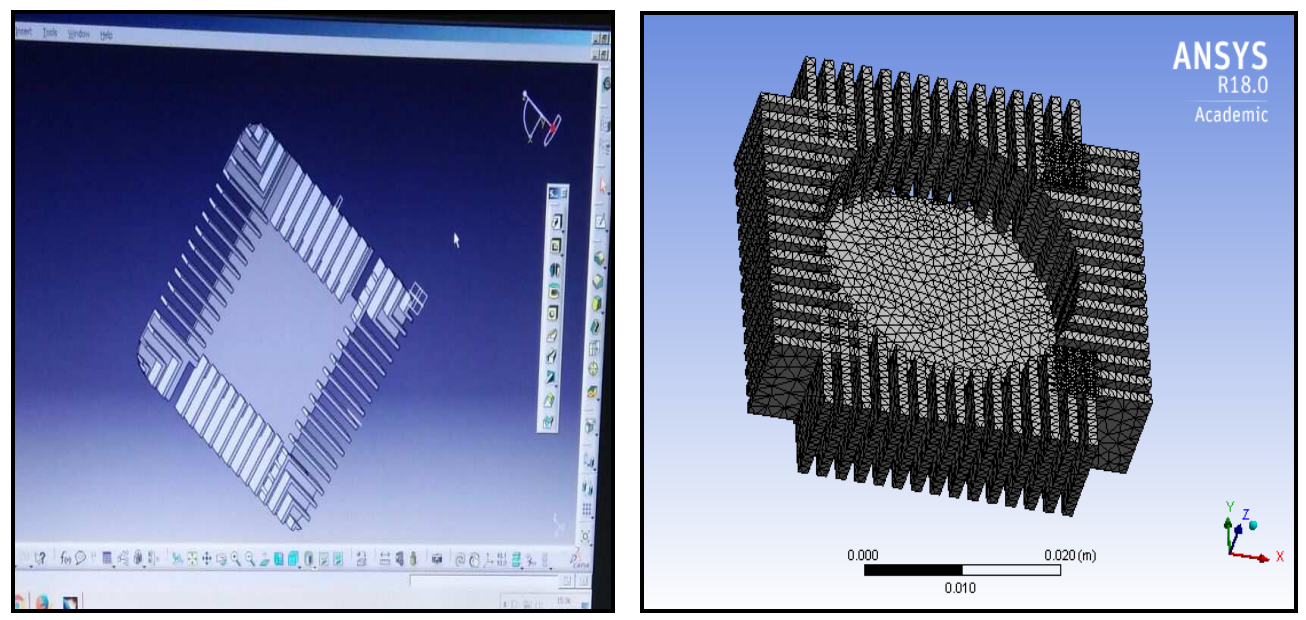

Figure 4: Modelling and Analysis of Copper Fin in Catia V5 and ANSYS
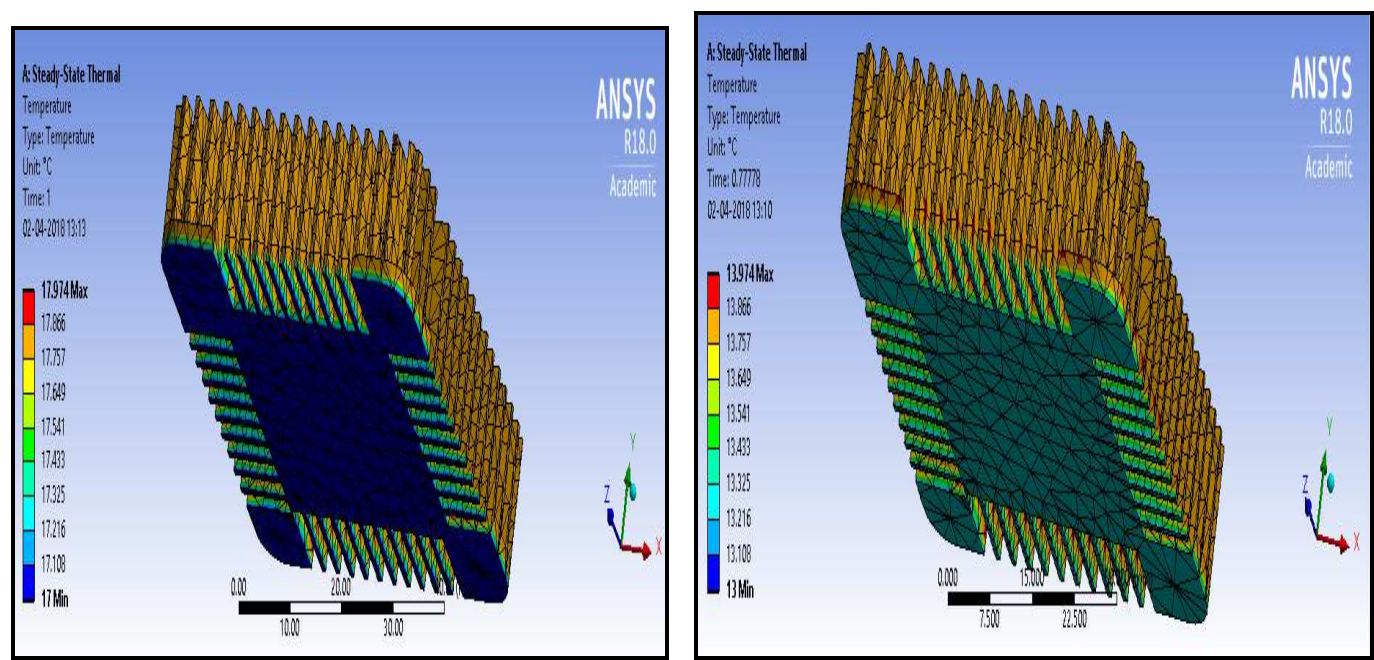

Figure 5: Comparison of Temperature Distributions in Copper Fin at 3 and 6 amps Current

Figure 5 shows that comparison has been made on Copper fin thermoelectric cooler module by applying 3 and 6 amps input power supply has given a cooling effect temperature of $17.97{ }^{0} \mathrm{C}$ and $13.97{ }^{0} \mathrm{C}$. It shows that higher cooling effect is observed when high input power supply is given and the reason is that large amount of heat rejection is taking place from cooler module. 

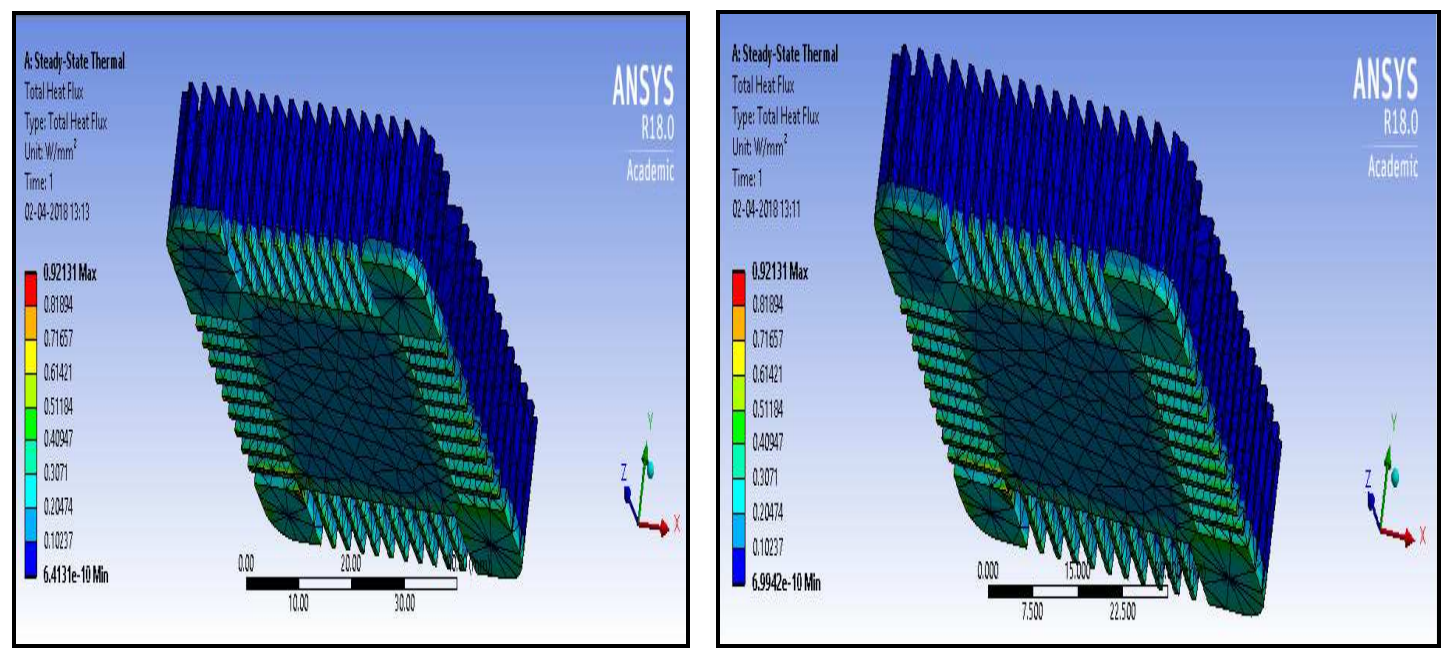

Figure 6: Heat Flux Distribution of Copper Fin at 3 and 6 amps Input Current

Heat flux distribution in Copper fins of thermoelectric cooler module is shown in figure 6 indicates that from TEC module to upper surface of the fin, the contour colours changes from blue to red based on temperature value. Heat flux means amount heat released for unit area of the copper fin from $6.4131 \mathrm{e}^{-10}$ to $6.92131 \mathrm{e}^{-10} \mathrm{~W} / \mathrm{mm}^{2}$ for a solar electric input power supply of 3 amps. Heat flux distribution is from $6.992 \mathrm{e}^{-10}$ to $6.92131 \mathrm{e}^{-10} \mathrm{~W} / \mathrm{mm}^{2}$ for an electric input power supply of 6 amps

\section{STEADY STATE THERMAL ANALYSIS OF LONG AND SHORT ALUMINIUM FIN}

Modeling and meshing of long Aluminium fin for thermoelectric cooler module is designed using CATIA Version 5 and in ANSYS is shown in figure 7. Temperature distribution takes place from TE module to the upper surface of the fin shown in figure 8 and the colour contours changes from blue to red based on temperature value. So $18.268{ }^{0} \mathrm{C}$ is attained at entrance of the cooling chamber for a copper fin with a temperature loss of $1.268{ }^{0} \mathrm{C}$ for the case of 6 amps input power supply and $14.55{ }^{\circ} \mathrm{C}$ at entrance of the cooling chamber in case of Aluminium fin. The surroundings temperature is maintained at $33{ }^{\circ} \mathrm{C}$. Heat flux distribution in Aluminium fins of thermoelectric cooler module is shown in figure 9 indicates that from TEC module to upper surface of the fin, the contour colours changes from blue to red based on temperature value. Heat flux means amount heat released for unit area of the Aluminium fin from 137.02 to $21328 \mathrm{~W} / \mathrm{mm}^{2}$ for an electric input power supply of 3 amps.
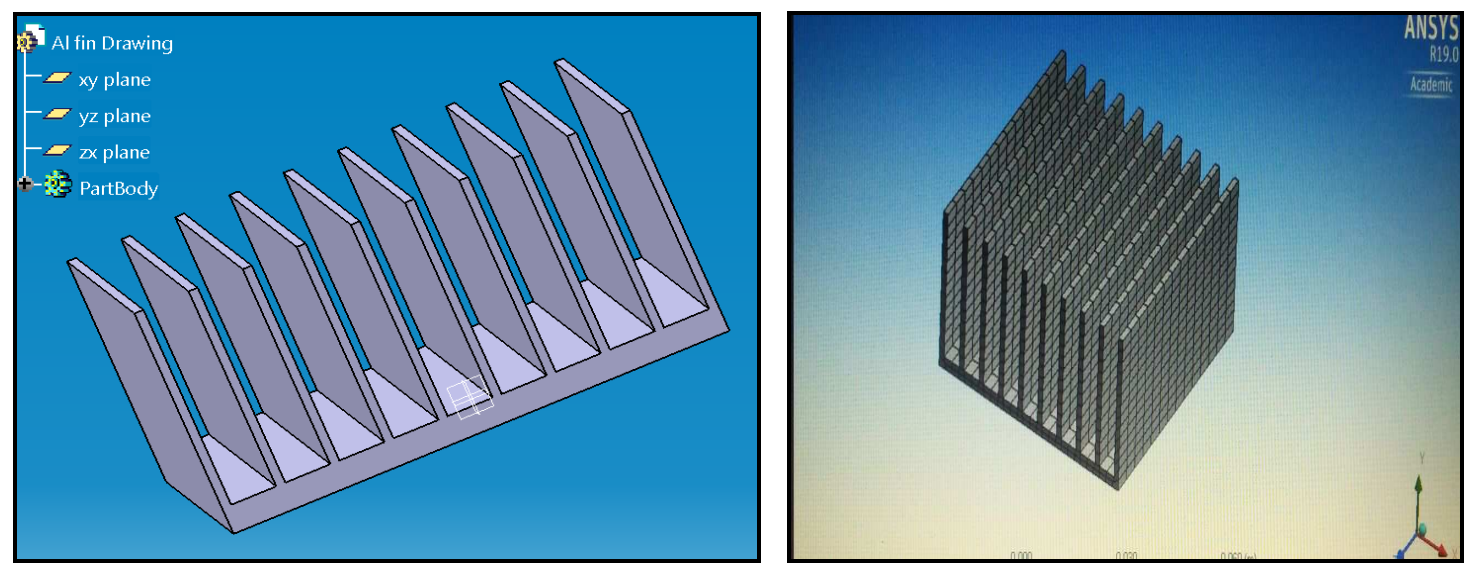

Figure 7: Modelling and Analysis of Long Aluminium Fin in CATIA and ANSYS 

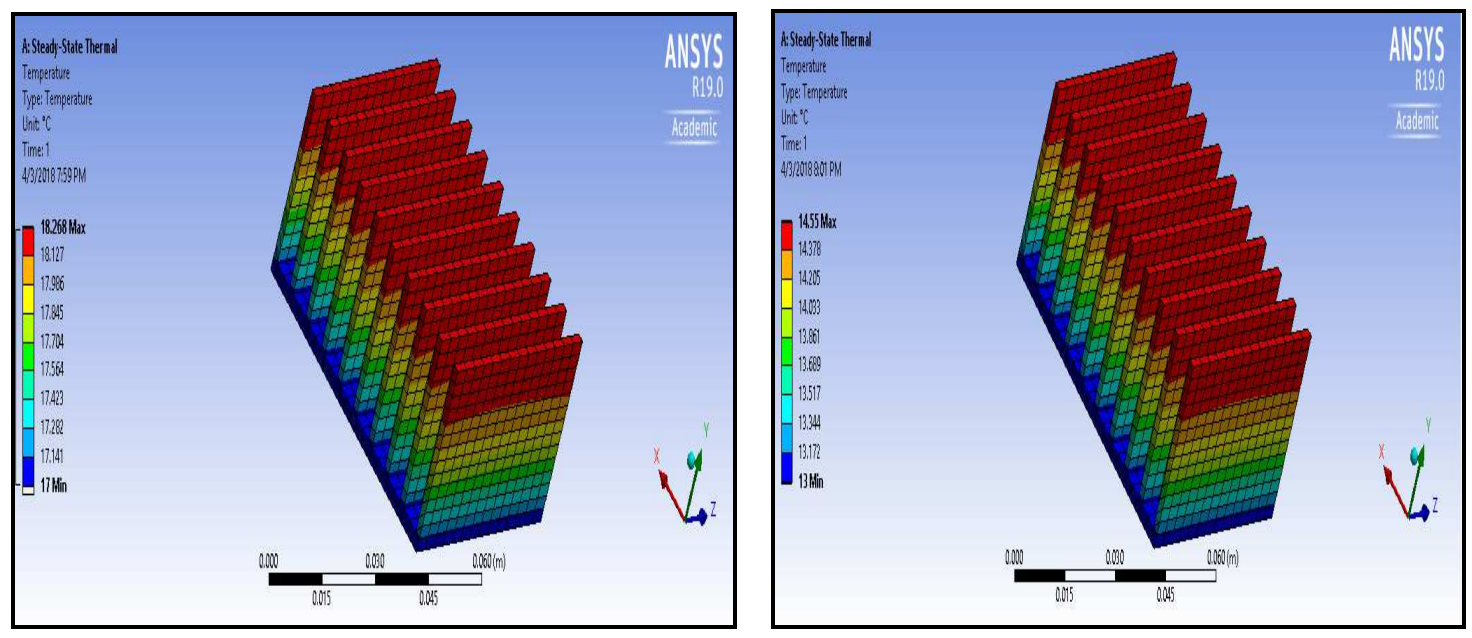

Figure 8: Temperature Distribution of Long Aluminium Fin at 3 and 6 amps Input Current
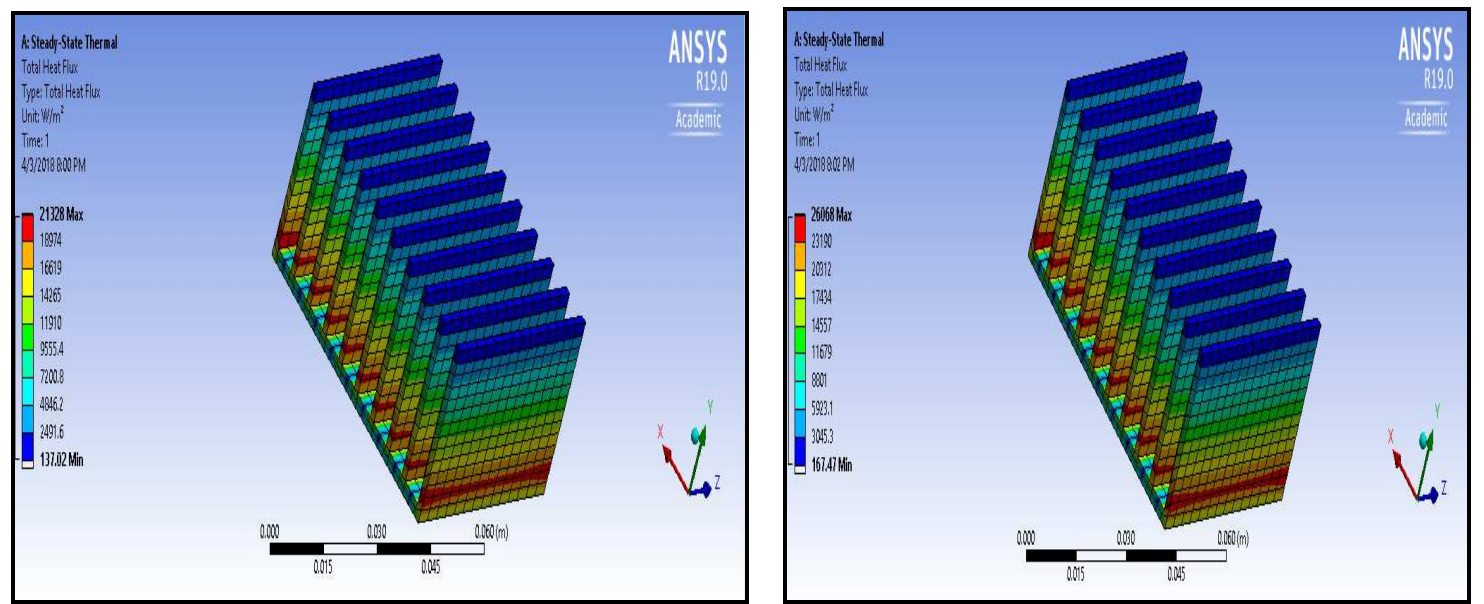

Figure 9: Heat Flux Distribution of Aluminium Fin at 3 and 6 amps Input Current

Heat flux distribution is from 167.48 to $26068 \mathrm{~W} / \mathrm{mm}^{2}$ for an electric input power supply of 6 amps. Hence it shows that more amount of heat flux distribution is taking place when high input electric power is supplied.
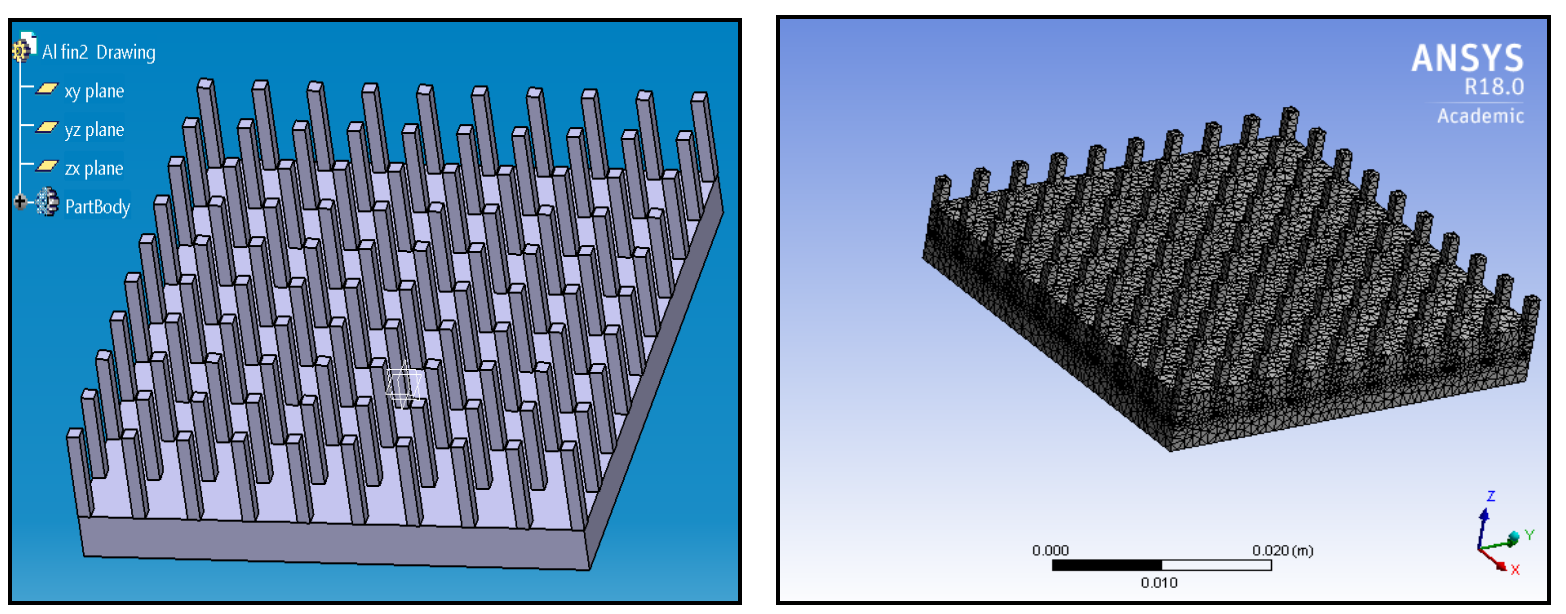

Figure 10: Modelling and Analysis of Short Aluminium Fin in CATIA and ANSYS 
Modelling and meshing of short Aluminium fin for thermoelectric cooler module is designed using CATIA Version 5 and in ANSYS is shown in figure 10.
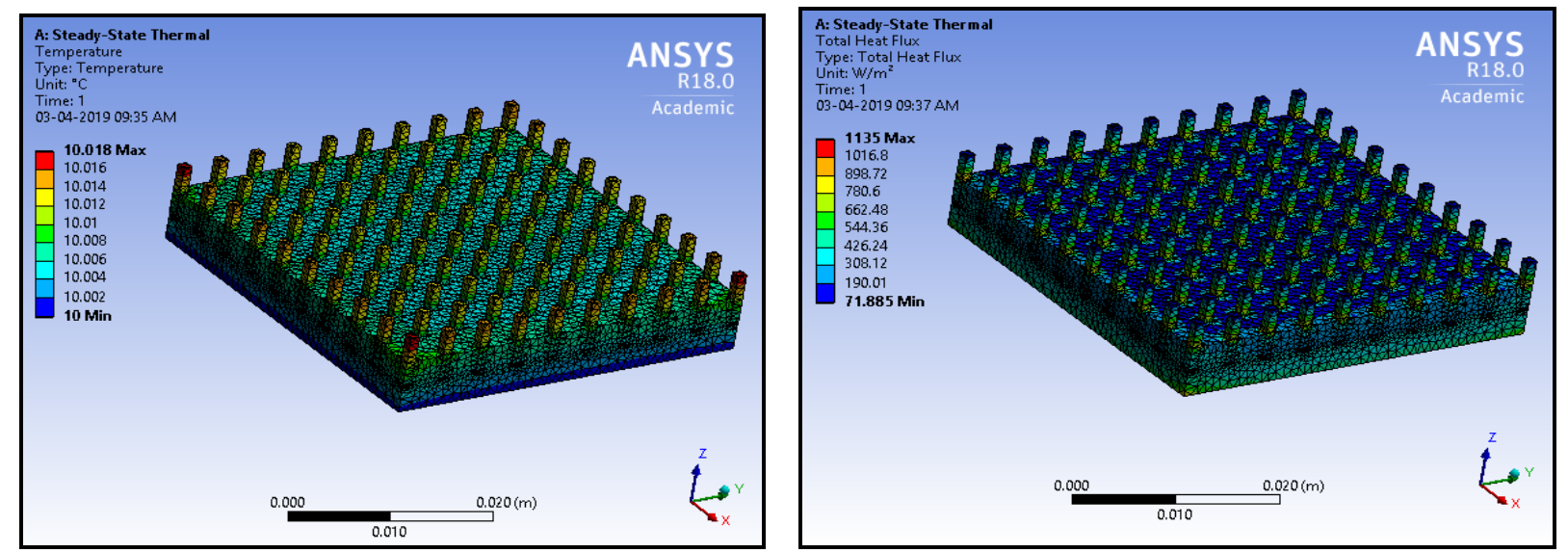

Figure 11: Temperature and Heat Flux Distribution in Short Aluminium Fin Using ANSYS

Temperature distribution takes place from TE module to upper surface of the fin is shown in figure 11. The color contours changes from blue to red based on temperature value. So in this case the temperatures attained are 10 ${ }^{0} \mathrm{C}$ at entrance of the cooling chamber and after reaching the temperature from bottom to top, the heat loss takes place around 0.018 at an ambient temperature $33{ }^{\circ} \mathrm{C}$. The solar electric power input supply is 6 amps.

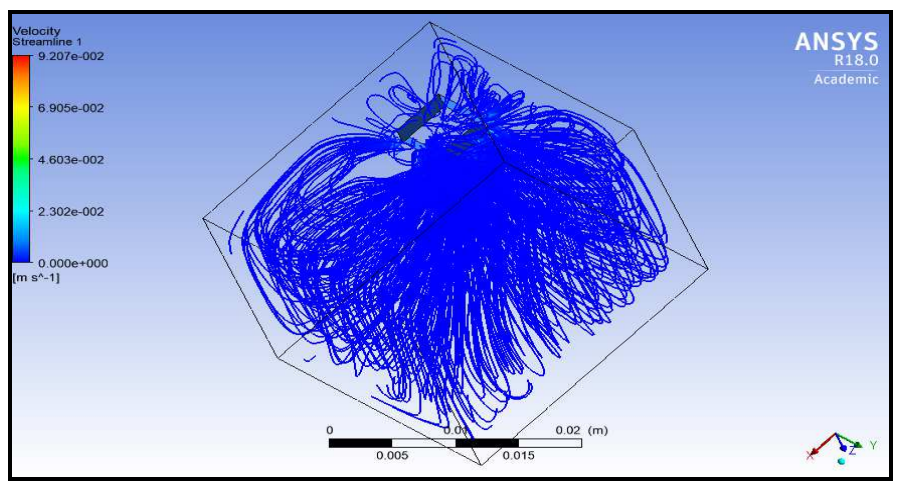

Figure 12: Cooling air Distribution in Cooling Chamber

Heat transfer takes place from module to cooling chamber is shown in figure 12 with some temperature distribution in the absence of fan at cold reservoir of TEC module. If the fan is placed on the cold reservoir, flow distribution will be different and will get more cooling in the cooling chamber.

\section{CONCLUSIONS}

This modelling and simulation of thermoelectric cooler module indicates with air-cooling with different sinks on cold reservoir like copper and aluminium fin materials. It is quite easy to achieve the significant temperature difference in the single stage TE module, but, the COP of the single stage module is very less for the domestic use. Cooling effect in cooling chamber is increased with increased electric current input to the TE module. Cooling effect is more in case of 6 amps solar energy input compared to 3 amps input. 
- The TE devices can act as coolers, heat pumps, power generators, or thermal energy sensors and are used in almost all the fields such as military, aerospace, instrument, biology, medicine, industrial or commercial products. The major challenge faced in TE cooling is lower COP especially in large capacity systems.

- It can be concluded that by selecting good materials for thermoelectric module and heat sinks, efficiency is still further improved and by providing the thermoelectric modules in series the efficiency can also rise further.

- With the increase of temperature differences between the junctions, so that the efficiency of thermoelectric module is increased.

\section{REFERENCES}

1. ElCosnier W., Gilles M., Lingai., “An experimental and numerical study of a thermoelectric air-cooling and air-heating system”. International journal of refrigeration, 31, 1051 - 1062, (2008).

2. Sujin., Vora and Seetawan., "Analysing of Thermoelectric Refrigerator Performance”, Proceedings of the 2ndInternational Science, Social-Science, Engineering and Energy Conference, 25,154-159, (2000).

3. Wei., Jinzhi., Jingxin \& Chen., "Theoretical and experimental investigation on a thermoelectric cooling and heating system driven by solar", Applied Energy, 107, 89-97, (2013).

4. Riffat and Guoquan., "Comparative investigation of thermoelectric air- conditioners versus vapour compression and absorption air- conditioners", Journal of Applied Thermal Engineering, 24, 1979-1993, (2004).

5. www.tetech.com / cool@tetech.com Procedure for Mounting Modules with Thermal Paste.

6. Ritzer, T. M, Nagy, M. J. and Lau, P.G., “Economic Optimization of Heat Sink Design” in Proceeding of the XIII International Conference on Thermoelectric, Kansas City, Missouri, USA, 1994

7. Riffat and Qiu., "Design and characterization of a cylindrical water cooled heat sink for thermoelectric air conditioners". International journal of energy research, 30, 67-80, (2005).

8. Astrain D., Vian J.G., and Dominguez M., "Increase of COP in the thermoelectric refrigeration by the optimization of heat dissipation", Applied Thermal Engineering, 23, 2183-2200, (2003).

9. Geete, A., \& Khandwawala, A. I. (2014). Exergy analysis for 120MW thermal power plant with different inlet temperature conditions. International Journal of Research in Engineering \& Technology, 2(1), 21-30.

10. Shen., Xiao., Chen \& Wang., "Investigation of a novel thermoelectric radiant air-conditioning system”, Journal of Energy and Buildings, 59, 123-132, (2012).

11. Virjoghe., Diana., Marcel \& Florin., “Numerical simulation of Thermoelectric System. Latest trends on systems”,15(2), 630635, (2009).

12. Maneewan., Tipsaenpromand Lertsatitthanakorn., "Thermal comfort study of a compact thermoelectric air conditioner", Journal of electronic materials, 39(9), 1659-1664, (2010).

13. Manoj S., \& Walke., "Thermoelectric Air Cooling for Cars”. International Journal of Engineering Science and Technology, 40(5), 2381-2394, (2011).

14. Yadav and Nirves., "Review on Thermoelectric materials and applications". International Journal for Scientific Research \& Development, 1,413-417, (2013). 
15. Matharou, G. S., Bhatia, S., \& Tanzeel, M. Comparative Study Of Sae 1141 Carbon Steel, T651-7075 Aluminum Alloy \& 4340 Billet Steel Material For Connecting Rod Using Ansys 16.

16. Manoj Kumar., Chattopadhyay and Neogi., "A review on developments of thermoelectric refrigeration and air conditioning systems: a novel potential green refrigeration and air conditioning technology". International Journal of Emerging Technology and Advanced Engineering, 38,362-367, (2013).

17. Huang B., Chin C.J., and Duang C.L., "A design method of thermoelectric cooler" International Journal of Refrigeration, 23,208-218, (1999). 